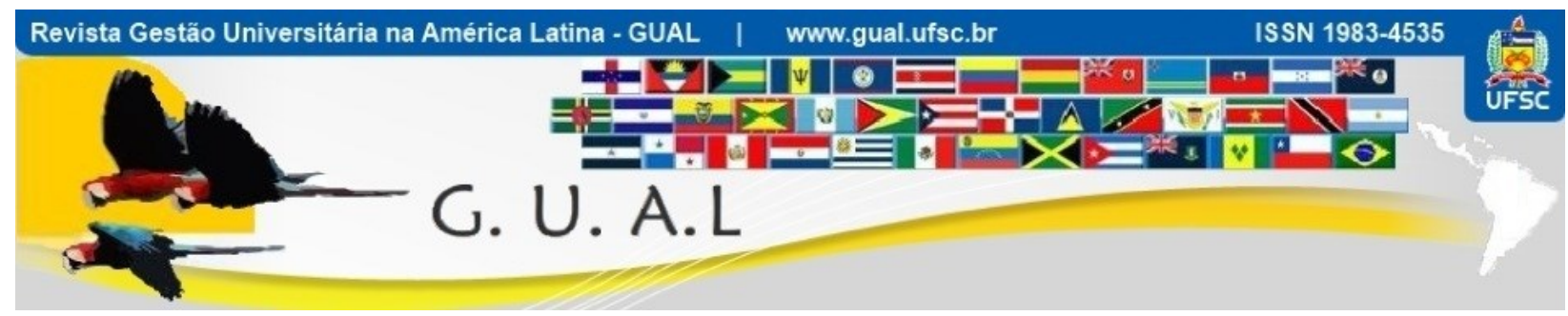

DOI: http://dx.doi.org/10.5007/1983-4535.2018v11n2p110

\title{
O MODELO DA HÉLICE TRÍPLICE: PRODUÇÃO INTELECTUAL EM PERIÓDICOS NACIONAIS E INTERNACIONAIS
}

\section{MODEL TRIPLE HELIX: INTELLECTUAL PRODUCTION IN INTERNATIONAL AND NATIONAL JOURNALS}

Denise Isabel Rizzi, Doutoranda Universidade Federal de Santa Catarina - UFSC deniserizzi@unochapeco.edu.br

Sady Mazzioni, Doutor Universidade Comunitária da Região de Chapecó - UNOCHAPECÓ sady@unochapeco.edu.br

Odilon Luiz Poli, Doutor Universidade Comunitária da Região de Chapecó - UNOCHAPECÓ odilon@unochapeco.edu.br

Geovanne Dias de Moura, Doutor Universidade Comunitária da Região de Chapecó - UNOCHAPECÓ geomoura@terra.com.br

Recebido em 19/julho/2016

Aprovado em 20/fevereiro/2018

Sistema de Avaliação: Double Blind Review

Esta obra está sob uma Licença Creative Commons Atribuição-Uso. 


\title{
RESUMO
}

O objetivo do estudo é analisar a produção intelectual, nacional e internacional, sobre a temática relacionada com o modelo da hélice tríplice. Quanto aos procedimentos metodológicos, o estudo pode ser caracterizado como descritivo e com abordagem quantitativa. Para identificar os artigos publicados sobre o tema, foram utilizadas as bases Scopus e Sciencedirect no contexto internacional e as bases Spell e Scielo, no âmbito nacional, totalizando uma amostra de 356 artigos. Os principais achados indicam que: o período de publicação ocorreu a partir de 1990, com crescimento expressivo a partir do ano de 2010; os principais autores do tema são H. Etzkowitz e L. Leydesdorft; a maior frequência nas publicações analisadas é a presença de dois autores por obra. A partir da análise dos resultados foi possível verificar o notório crescimento no interesse dos pesquisadores em relação à temática do modelo da hélice tríplice.

Palavras-chave: Estudo bibliométrico. Hélice tríplice. Universidade-empresa.

\begin{abstract}
The objective of the study is to analyze the intellectual, national and international production, on the theme related to the model of the triple helix. As for the methodological procedures, the study can be characterized as descriptive and quantitative approach. To identify the published articles, we used the Scopus and ScienceDirect databases in the international context and Spell and Scielo bases at the national level, for a total sample of 356 articles. The main findings indicate that: the publication period was from 1990, with significant growth from the year 2010; the main theme of the authors are H. and L. Etzkowitz Leydesdorft; the highest frequency in the analyzed publications is the presence of two authors of the work. From the analysis of the results it was possible to verify the apparent increase in the interest of researchers in relation to the theme of the triple helix model.
\end{abstract}

Keywords: Bibliometric study. Triple Helix. Universities and companies. 


\section{O MODELO DA HÉLICE TRÍPLICE: \\ PRODUÇÃO INTELECTUAL EM PERIÓDICOS NACIONAIS E INTERNACIONAIS \\ DOI: http://dx.doi.org/10.5007/1983-4535.2018v11n2p110}

\section{INTRODUÇÃO}

Com a introdução da pesquisa na estrutura organizacional, as Instituições de Ensino Superior (IES) ampliaram seu papel na sociedade, agregando maior importância para o desenvolvimento no ambiente em que estão inseridas. Cunha (2002) afirma que essa nova situação contribuiu ainda mais para a importância das universidades no desenvolvimento econômico, auxiliou na aplicação prática dos conceitos curriculares e na comunicação dos conhecimentos gerados internamente nas escolas superiores.

A interação da transferência de tecnologia universidade-empresa, por agregar vantagens estratégicas em muitos países, representou fonte de recursos para as pesquisas acadêmicas, inovação para as empresas e, em consequência, desenvolvimento econômico para os governos (MUSCIO, 2010).

A interação entre a universidade, a indústria e o governo é a chave para a inovação e o crescimento em uma economia baseada no conhecimento (ETZKOWITZ, 2013). Essa tríplice aliança, universidade-indústria-governo, consiste na base matricial do modelo da hélice tríplice, proposto pelos sociólogos Etzkowitz e Leydesdorff (1996), em que a universidade fornece capital humano, o governo define a regulação e a indústria produz bens e serviços (KIM; LEE, 2016)

O modelo da hélice tríplice foi gerado a partir de uma análise da relação do governo com a universidade e a indústria em diferentes sociedades e de seus vários papéis na inovação (ETZKOWINTZ; LEYDESDORFF, 2000). A ideia geral é que as interações entre universidade, indústria e governo são fundamentais para melhorar as condições tecnológicas, institucionais e psicológicas para a inovação (PHILLIPS, 2014; KIM; LEE, 2016).

No Brasil, a Lei de Inovação (Lei Federal n. ${ }^{\circ}$ 10.973/2004) facilitou e fortaleceu as iniciativas de parcerias entre instituições de pesquisa, universidades e as indústrias, buscando reforçar suas relações e incentivar a inovação. Esta Lei representa o mecanismo legal do governo para aumentar o número de registros de patentes no país, proporcionando maiores vínculos e propagando ideias com potenciais inovadores (CORTEZIA, 2007).

Em certa medida, a inovação tem se fundamentado no modelo da hélice tríplice, tomando forma por meio das incubadoras, parques científicos e empresas de capital de risco interligados às universidades. As incubadoras, conforme Tisott et al. (2014), constituem um mecanismo de estímulo à criação e ao desenvolvimento de micro e pequenas empresas 


\section{O MODELO DA HÉLICE TRÍPLICE: \\ PRODUÇÃO INTELECTUAL EM PERIÓDICOS NACIONAIS E INTERNACIONAIS \\ DOI: http://dx.doi.org/10.5007/1983-4535.2018v11n2p110}

industriais ou de prestação de serviço, de base tecnológica ou manufaturas leves, sendo que este processo ocorre por meio da capacitação dos empreendedores.

A partir da importância atribuída ao modelo da hélice tríplice para a formação de novos empreendimentos e no desenvolvimento econômico, é possível que pesquisadores de diferentes áreas do conhecimento tenham passado a conduzir seus estudos com foco nos benefícios proporcionados na interação deste modelo nas organizações. Além disso, a crescente importância do modelo levou ao surgimento de um rico corpo de investigação teórica e empírica (CHUNG; PARK, 2014).

Nesse sentido, de acordo com Chung e Park (2014), a beleza das pesquisas sobre hélice tríplice reside na sua diversidade e inovação, refletindo as características dinâmicas da abordagem. A relevância deste tema pode ser avaliada mediante a identificação das repercussões da temática no interesse dos pesquisadores em investigá-la, tendo o estudo bibliométrico uma contribuição importante.

O estudo bibliométrico possibilita desvendar o estado da arte da temática proposta no meio científico e acadêmico. A bibliometria permite, mediante a geração de índices, avaliar a produção científica de um país, das instituições e dos cientistas. Este tipo de investigação possibilita macro análises, como a da produção científica de um país em relação ao mundo, e também microanálises, a exemplo da relação entre a produção acadêmica de um pesquisador e a comunidade científica na qual está inserido (MACIAS-CHAPULA, 1998).

Neste estudo, a análise bibliométrica é aplicada para responder ao seguinte problema de pesquisa: quais as características da produção intelectual em periódicos nacionais e internacionais, relacionadas à temática do modelo da hélice tríplice? Em linha com o problema proposto, o objetivo da investigação é analisar a produção intelectual, nacional e internacional, sobre a temática relacionada com o modelo da hélice tríplice.

Klevorick et al. (1995) apresentam evidências empíricas sobre o papel das universidades e da ciência como uma importante fonte de oportunidades tecnológicas para a inovação industrial. Deste modo, o envolvimento das três esferas (universidade-empresagoverno) atua como facilitador do processo de inovação, gerando benefícios para todos os envolvidos, diretamente ou indiretamente.

É pertinente destacar que estudos com esse tipo de abordagem se justificam pela construção de uma base contextual sobre a temática do modelo da hélice tríplice, contribuindo com a promoção da inovação e o desenvolvimento da sociedade, além de fomentar novos 


\section{O MODELO DA HÉLICE TRÍPLICE: \\ PRODUÇÃO INTELECTUAL EM PERIÓDICOS NACIONAIS E INTERNACIONAIS \\ DOI: http://dx.doi.org/10.5007/1983-4535.2018v11n2p110}

negócios. Etzkowitz (2013) argumenta que a inovação assume um novo significado quando ocorre o entrelaçamento das espirais da hélice tríplice.

O presente artigo está estruturado em mais cinco seções. Na segunda seção expõe-se o campo da pesquisa referente à temática do modelo da hélice tríplice; na terceira seção contempla-se o contexto sobre os estudos bibliométricos; na quarta seção descreve-se a metodologia dispensada à condução da investigação; na quinta seção, expõe-se a análise da pesquisa, sob os enfoques dos autores e das instituições. Na última seção, constam as considerações finais do estudo e as sugestões para o desenvolvimento de pesquisas futuras.

\section{REVISÃO DA LITERATURA}

A revisão da literatura apresenta os conceitos que fundamentam o assunto pesquisado e que servem de base para análise dos dados coletados.

\subsection{O MODELO DA HÉLICE TRÍPLICE}

O modelo da hélice tríplice começa quando a universidade, a indústria e o governo dão início a um relacionamento recíproco, no qual cada um tenta melhorar o desempenho do outro. Essas ligações geralmente ocorrem em níveis regionais, onde contextos específicos de clusters industriais, desenvolvimento acadêmico e presença ou falta da autoridade governamental influenciam no desenvolvimento da hélice tríplice (ETZKOWITZ, 2013).

O conceito de hélice tríplice, a partir das relações indústria-governo-universidade, foi iniciado na década de 1990 por Etzkowitz (1993) e Etzkowitz e Leydesdorff (1995) (VERLINDE, MACHARIS, 2016). Surgiu, segundo Verlinde e Macharis (2016), como um quadro de referência para a análise dos sistemas de inovação e para fornecer uma estrutura que fosse capaz de descrever as relações múltiplas e recíprocas entre os três principais agentes no processo de criação de conhecimento e capitalização: universidades, indústrias e governos.

O pensamento principal é que a inovação acontece na intersecção de três espaços institucionais (indústria, estado e pesquisas) e que, em oposição aos modelos de inovação anteriores, havia um importante papel a ser desempenhado pelas universidades e que precisava ser considerado também (VERLINDE; MACHARIS, 2016).

O processo de inovação se depara com um arsenal de obstáculos para seu desencadeamento, para isso há necessidade da interação do governo, da estrutura produtiva e das instituições de ciência e tecnologia. A atuação do governo visa à formulação e 
implementação de políticas no âmbito científico-tecnológico de forma deliberada; as instituições de ensino, são as responsáveis pela capacidade criadora, desenvolvendo a ciência e a tecnologia. A estrutura produtiva tem como função revolucionar o sistema de produção, através de inovações. Desta forma, a junção do governo serve como um propulsor da inovação, com o objetivo de diminuir o atraso tecnológico em relação aos países mais desenvolvidos (SCHREIBER et al., 2013).

$\mathrm{O}$ modelo da hélice tríplice de relações universidade-indústria-governo, define o governo como agente principal na promoção da interação entre as indústrias e as universidades que apresentavam papéis institucionais separados e distintos. Mais recentemente, as universidades passaram a receber incentivos governamentais, e pressão das indústrias, de maneira a fomentar um desempenho superior nas suas atividades e funções tradicionais (ETZKOWITZ; LEYDESDORFF, 1998).

A hélice tríplice da inovação apresenta a interação entre os atores através de espirais, nas quais novas e complexas relações se estabelecem nas três hélices: universidade, empresa e governo. Estes ambientes se transformaram em um "espaço de inovação" e as relações derivam das mutações internas de cada hélice, da influência de uma sobre as outras e do surgimento de novas redes (ETZKOWITZ; LEYDESDORFF, 2000). A Figura 1 apresenta o atual modelo da hélice tríplice, evidenciando melhor essa interação.

Figura 1 Modelo de interação da hélice tríplice

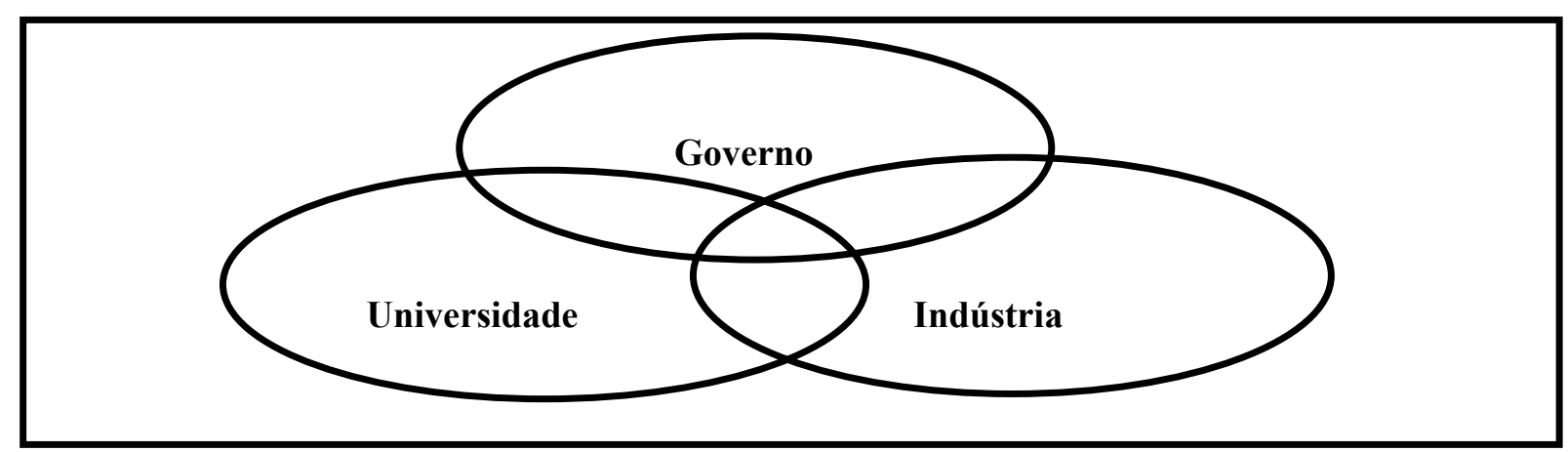

Fonte: Etzkowitz (2013).

De modo geral, as empresas visam gerar riqueza econômica, os governos querem controlar seu território para mantê-lo atraente para todos os atores e as universidades têm como objetivo desenvolver novidades (STRAND; LEYDESDORFF, 2013). Todavia, nota-se na Figura 1 que as esferas encontram-se sobrepostas, gerando intersecções e demonstrando 


\section{O MODELO DA HÉLICE TRÍPLICE: \\ PRODUÇÃO INTELECTUAL EM PERIÓDICOS NACIONAIS E INTERNACIONAIS \\ DOI: http://dx.doi.org/10.5007/1983-4535.2018v11n2p110}

que pode haver certa atuação de um ator na área do outro, estabelecendo condições de uma relação verdadeiramente produtiva.

Ao se observar a interação "governo-universidade", depara-se com políticas que afetam as questões da academia, como a Lei da Inovação (BRASIL, 2002), que surge como instrumento de flexibilização de trocas e autorização de exercício simultâneo de atividades, afetando principalmente as universidades públicas federais. Entre os benefícios desta Lei, destaca-se a criação de Núcleos de Inovação Tecnológica (NIT), com o objetivo de introduzir uma nova dinâmica na gestão das relações das universidades com o setor produtivo (DUDZIAK; PLONSKY, 2008; SANTOS, 2008).

Considerando a intersecção "governo-indústria", pode-se exemplificar, na realidade brasileira, o desenvolvimento pela Financiadora de Estudos e Projetos (FINEP) de linhas de financiamento diretamente para o setor produtivo. A empresa é a organização que detém a lógica para a criação de produtos inovadores com vocação comercial, o que the confere importância estratégica, principalmente as pequenas e médias, no desenvolvimento socioeconômico brasileiro, dado seu elevado potencial gerador de empregos, trabalho e renda (SBRAGIA et al., 2006; CLOSS; FERREIRA, 2010).

No que tange a intersecção entre a "universidade-indústria", essa união revela o desenvolvimento de inúmeras pesquisas e patentes conjuntas, além do licenciamento de tecnologias (SORIA, 2011). Schreiber et al. (2013) argumentam que essa parceria propicia condições favoráveis para a revisão da atuação estratégica das organizações, com base na constituição de diferencial competitivo, com foco na inovação de produtos e processos, em decorrência à interação universidade-empresa, em especial para as empresas inseridas em redes de cooperação.

Silva e Votre (2012) direcionam o papel da universidade como formadora de agentes multiplicadores. O governo atua para criar, aperfeiçoar, fomentar e consolidar políticas públicas, tendo a empresa como coautora. Ao destacar-se o papel destas três esferas, induz-se à necessidade desta aliança na promoção do desenvolvimento regional.

\subsection{ESTUDO BIBLIOMÉTRICO}

O surgimento dos estudos bibliométricos em artigos científicos ocorreu em 1922 por Dresden. A introdução deste termo teve como interesse a construção de uma nova disciplina científica. Na Argentina, Buonocore (1952) introduz o termo bibliometria com a definição de 


\section{O MODELO DA HÉLICE TRÍPLICE: \\ PRODUÇÃO INTELECTUAL EM PERIÓDICOS NACIONAIS E INTERNACIONAIS \\ DOI: http://dx.doi.org/10.5007/1983-4535.2018v11n2p110}

uma técnica que tem por objeto calcular a extensão ou medida dos livros, tomando como base diversos coeficientes: formato, tipo de letra, quantidade de palavras, peso do papel, entre outros (ALVARADO, 2007).

A pesquisa bibliométrica, utilizando técnicas quantitativas e estatísticas de medição dos índices de produção e disseminação do conhecimento científico, estuda e avalia as atividades de produção e comunicação científica (ARAÚJO, 2006), permitindo conhecer de modo mais aprofundado uma determinada temática e seu estado da arte.

Inicialmente, o termo bibliometria foi utilizado em estudos que procuravam quantificar os produtos da atividade científica (livros, artigos e revistas), para fins de gestão de bibliotecas e bases de dados (SANTOS; KOBASHI, 2009). Na sequência, surgiu uma diversidade de leis e conceitos relacionados à bibliometria, em que as principais são as Leis de Bradford, Lotka e Zipf. A Lei de Bradford tem foco na produtividade de periódicos, a Lei de Lotka na produtividade científica de autores e a Lei de Zipf na frequência de palavras (GUEDES; BORSCHIVER, 2005).

O Quadro 1 apresenta as medidas estatísticas para o cálculo da Lei Lotka, de Bradford e de Zipf.

Quadro 1 Leis bibliométricas

\begin{tabular}{|l|l|l|}
\hline \multicolumn{1}{|c|}{ Lei de Lotka } & \multicolumn{1}{|c|}{ Lei de Bradford } & \multicolumn{1}{c|}{ Lei de Zipf } \\
\hline$Y_{\mathrm{n}}=X_{1} \frac{1}{n^{2}}$ & $\begin{array}{l}\text { Listar os periódicos com o } \\
\text { número de artigos de cada um, } \\
\text { em ordem decrescente, com } \\
\text { soma parcial. O total de artigos } \\
\text { deve ser somado e dividido por }\end{array}$ & $\frac{I_{1}}{l_{n}}=\frac{n(n+1)}{2}$ \\
$\begin{array}{l}\mathrm{Y}=\text { frequência de autores que } \\
\text { publicam N número de artigos; } \\
\mathrm{X} 1=\text { quantidade de autores que } \\
\text { publicaram 1 único artigo; } \mathrm{n}= \\
\text { total de autores para o qual se } \\
\text { deseja conhecer o valor de } \mathrm{Y} .\end{array}$ & $\begin{array}{l}\text { artigos, até o total de 1/3 dos } \\
\text { artigos, é o "core" daquele } \\
\text { assunto. O segundo e o terceiro } \\
\text { grupo são as extensões. }\end{array}$ & $\begin{array}{l}\mathrm{I} 1=\text { número de palavras que } \\
\text { de palavras que têm frequência } \\
\mathrm{n} ; 2=\text { constante válida para a } \\
\text { língua inglesa. }\end{array}$ \\
\hline
\end{tabular}

Fonte: Guedes, Borschiver (2005) e Araújo (2006).

A Lei de Lotka dedica-se a prever a produtividade dos cientistas por meio da contagem dos autores. De acordo com a referida Lei, uma grande quantidade de produção científica é gerada por um pequeno grupo de pesquisadores e o volume de produção gerado por tais pesquisadores se iguala ao total de produção do grande grupo de produtores (GUEDES; BORSCHIVER, 2005). 


\section{O MODELO DA HÉLICE TRÍPLICE: \\ PRODUÇÃO INTELECTUAL EM PERIÓDICOS NACIONAIS E INTERNACIONAIS \\ DOI: http://dx.doi.org/10.5007/1983-4535.2018v11n2p110}

A Lei de Bradford é anunciada da seguinte forma: "se dispormos periódicos em ordem decrescente de produtividade de artigos sobre um determinado tema, pode-se distinguir um núcleo de periódicos mais particularmente devotados ao tema e vários outros grupos ou zonas que incluem o mesmo número de artigos que o núcleo" (ARAÚJO, 2006, p. 15). Cada zona contém um terço do total dos artigos, porém, a quantidade de periódicos contidos em cada uma delas é diferente. Segundo Bates (1996), embora o número de artigos relevantes seja o mesmo nas três zonas, a quantidade de artigos relevantes, por periódico, diminui do núcleo para fora, ou seja, da $1^{\text {a }}$ para a $3^{\mathrm{a}}$ zona, e o número total de artigos relevantes sobre um tema é provavelmente um ajuste entre todas as zonas.

A Lei de Zipf descreve a relação entre palavras, ou seja, mede a frequência de palavras que aparecem em um texto. Segundo Mamfrim (1991) e Santos (2009), a Lei de Zipf relaciona-se com as palavras de alta frequência e postula que se as palavras de um texto forem colocadas em ordem decrescente, verificar-se-á que a ordem de uma série de palavras (R) multiplicadas por sua frequência $(F)$ produz uma constante $(K)$. Posteriormente, esta Lei foi atualizada conforme exposto no Quadro 1.

A pesquisa bibliométrica está orientada para “o estudo dos aspectos quantitativos da produção, disseminação e uso da informação registrada" (MACIAS-CHAPULA, 1998, p. 134). Os dados bibliográficos importados das bases de dados podem ser organizados e estudados com o uso de diferentes softwares para análise bibliométrica. Entre as suas funcionalidades está à organização de dados em arquivos de texto ou planilhas, possibilitando ao pesquisador a utilização de outros softwares e também a importação de diferentes tipos de dados (VANZ; STUMPF, 2010).

Assim, pesquisas desenvolvidas neste âmbito, abordando em seu contexto este método de estudo, torna-se um arsenal de fontes bibliográficas referentes à temática pesquisada, proporcionando ao leitor e ao pesquisador várias opções de entrelaçamento de assuntos e estudos na área desejada. Proporcionam, também, uma análise do estado da arte do tema, sua profundidade, repetições e o envolvimento dos pesquisadores já atuantes na área.

\section{METODOLOGIA}

Respeitando-se as peculiaridades do estudo, pode-se caracterizá-lo como descritivo em relação aos objetivos e quantitativo no que se refere à abordagem do problema. Pode ser classificado como descritivo por ter a pretensão de descrever aspectos relacionados à 


\section{O MODELO DA HÉLICE TRÍPLICE: \\ PRODUÇÃO INTELECTUAL EM PERIÓDICOS NACIONAIS E INTERNACIONAIS \\ DOI: http://dx.doi.org/10.5007/1983-4535.2018v11n2p110}

produção científica acerca da temática do modelo da hélice tríplice. Classifica-se com abordagem quantitativa pois o esse procedimento tem como propósito buscar informações reais para explicar em profundidade o significado e as características de cada contexto (LUDKE; ANDRÉ, 2013).

O estudo baseia-se em pesquisa bibliométrica, realizado por meio da análise de artigos publicados em periódicos indexados nas bases nacionais e internacionais. Para o contexto internacional, foram utilizadas as bases Scopus e Sciencedirect e, no âmbito nacional, as bases Spell e Scielo.

A coleta de dados ocorreu no mês de novembro de 2015 e considerou todo o período disponível nas bases consultadas. Na página de busca, nas bases nacionais, foram utilizados os termos "hélice tríplice" e "universidade-empresa", filtrando apenas no título do documento. Já nas bases internacionais, foi utilizado o termo "triple helix" localizado na opção títuloresumo-palavra-chave (title - abstract - keyword).

Nas bases internacionais foram contempladas as produções nas subáreas de Negócios, Gestão e Contabilidade (Business, Management and Accounting), Ciências da Decisão (Decision Sciences), Economia, Econometria e Finanças (Economics, Econometrics and Finance) e Ciências Sociais (Social Sciences). Nas bases nacionais, considerando-se que as produções são mais incipientes, não foram considerados filtros por áreas, utilizando-se dos retornos de toda a base. Ademais, a base Spell possui apenas artigos da área de Administração, Ciências Contábeis e Turismo, publicados a partir de 2008.

As pesquisas realizadas na base de dados da Scielo consideraram como filtro de busca os termos no título, em que a palavra-chave 'hélice tríplice' resultou em 2 artigos e com a palavra-chave 'universidade-empresa', foram localizados 23 artigos. Na base de dados da Spell, com o filtro de busca no título, o uso da palavra-chave 'hélice tríplice' resultou em 3 artigos e com a palavra-chave 'universidade-empresa' foram localizados 27 artigos.

Nas bases internacionais, a palavra-chave utilizada na pesquisa foi somente 'triple helix', por retornar resultados expressivos somente com esta combinação. O filtro utilizado foi na busca title-abstract-keyword. Na base da Scocus foram encontrados 247 artigos e na base Sciencedirect 54 artigos relacionados com o tema pesquisado, já excluídas as duplicidades e/ou falsas recuperações.

Para a seleção e análise dos dados efetuados neste estudo, a amostra ficou composta de 356 artigos, selecionados pelo uso de filtros e exclusões de alguns estudos por não 
condizerem com as expectativas relacionadas ao tema investigado. Os artigos recuperados foram tabulados e operacionalizadas por meio dos filtros de pesquisa das bases científicas já citadas e tratadas nos softwares Excel ${ }^{\circledR}$, EndNote X7 e Ucinet $6^{\circledR}$.

\section{ANÁLISE DOS RESULTADOS}

A seção de análise dos resultados está pautada na investigação dos 356 artigos que compõem os achados da pesquisa, a qual considerou todos os períodos disponíveis nas bases de acesso. A descrição da análise dos dados segue a seguinte ordem: i) evolução quantitativa da produção; ii) periódico por ano; iii) coautoria entre os autores; iv) quantidade de autores por artigos; v) impacto dos artigos; vi) artigos por linguagem; vii) Lei de Lotka; viii) Lei de Bradford e ix) Lei de Zipf.

No tocante ao volume de publicações anuais com a temática "modelo da hélice tríplice”, voltado para a interação entre universidade-empresa-governo, são apresentados na Tabela 1 os resultados advindos desta pesquisa.

Tabela 1 Distribuição da amostra

\begin{tabular}{c|c|c|c|c|l}
\hline Ano & $\mathbf{N}$ & $\mathbf{\%}$ & Ano & $\mathbf{N}$ & $\mathbf{\%}$ \\
\hline 1990 & 2 & $0,56 \%$ & 2005 & 6 & $1,69 \%$ \\
1994 & 1 & $0,28 \%$ & 2006 & 15 & $4,21 \%$ \\
1995 & 2 & $0,56 \%$ & 2007 & 14 & $3,93 \%$ \\
1996 & 2 & $0,56 \%$ & 2008 & 12 & $3,37 \%$ \\
1997 & 4 & $1,12 \%$ & 2009 & 18 & $5,06 \%$ \\
1998 & 2 & $0,56 \%$ & 2010 & 32 & $8,99 \%$ \\
1999 & 8 & $2,25 \%$ & 2011 & 24 & $6,74 \%$ \\
2000 & 11 & $3,09 \%$ & 2012 & 58 & $16,29 \%$ \\
2001 & 4 & $1,12 \%$ & 2013 & 33 & $9,27 \%$ \\
2002 & 4 & $1,12 \%$ & 2014 & 40 & $11,24 \%$ \\
2003 & 13 & $3,65 \%$ & 2015 & 48 & $13,48 \%$ \\
\cline { 4 - 6 } 2004 & 3 & $0,84 \%$ & TOTAL & $\mathbf{3 5 6}$ & $\mathbf{1 0 0 \%}$ \\
\hline
\end{tabular}

Fonte: Dados da pesquisa
Gráfico 1 Distribuição da produção no período

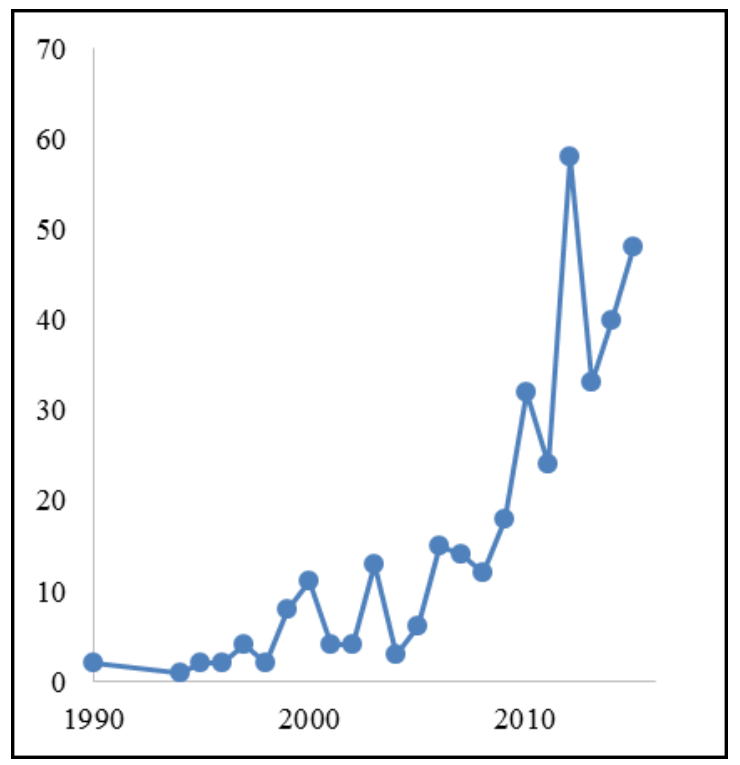

Fonte: Dados da pesquisa

Conforme identificado na Tabela 1, a partir do ano 2000 o assunto do modelo da hélice tríplice e a interação entre universidade-empresa começou a despertar maior interesse 


\section{O MODELO DA HÉLICE TRÍPLICE: \\ PRODUÇÃO INTELECTUAL EM PERIÓDICOS NACIONAIS E INTERNACIONAIS \\ DOI: http://dx.doi.org/10.5007/1983-4535.2018v11n2p110}

no mundo acadêmico e as publicações aumentaram. Com 58 artigos, o ano de 2012 apresenta a maior incidência de publicações, frequência que correspondente de $16,29 \%$ das publicações encontradas. Na elaboração da pesquisa não foi considerado um corte temporal inicial, incluindo-se todo o período coberto pelas bases utilizadas. Os achados evidenciaram que o assunto começou a ser publicado a partir do ano de 1990, ano em que 2 artigos foram publicados.

A partir de 1990, os estudos de H. Etzkowitz, atualmente considerado um dos principais nomes da temática hélice tríplice, aprofundaram-se na questão sobre proteção e capitalização do conhecimento e na correlação com as interações da universidade-indústria. No início desta década, os estudos passaram a considerar o papel das universidades em iniciativas governamentais para o apoio a pequenas e médias empresas e para o desenvolvimento regional baseado na ciência (ETZKOWITZ, 2013).

A distribuição evolutiva das produções apresentadas na Tabela 1 podem ser evidenciadas de modo mais claro no Gráfico 1, onde visualiza-se o crescimento desta temática no ambiente acadêmico.

A Figura 2 demonstra o vínculo dos principais periódicos ligados aos correspondentes anos da publicação, desde 1990 até 2015. Esses dados possibilitam a compreensão e uma visualização da divulgação sobre a temática abordada.

Figura 2 Visualização da rede de revistas por ano

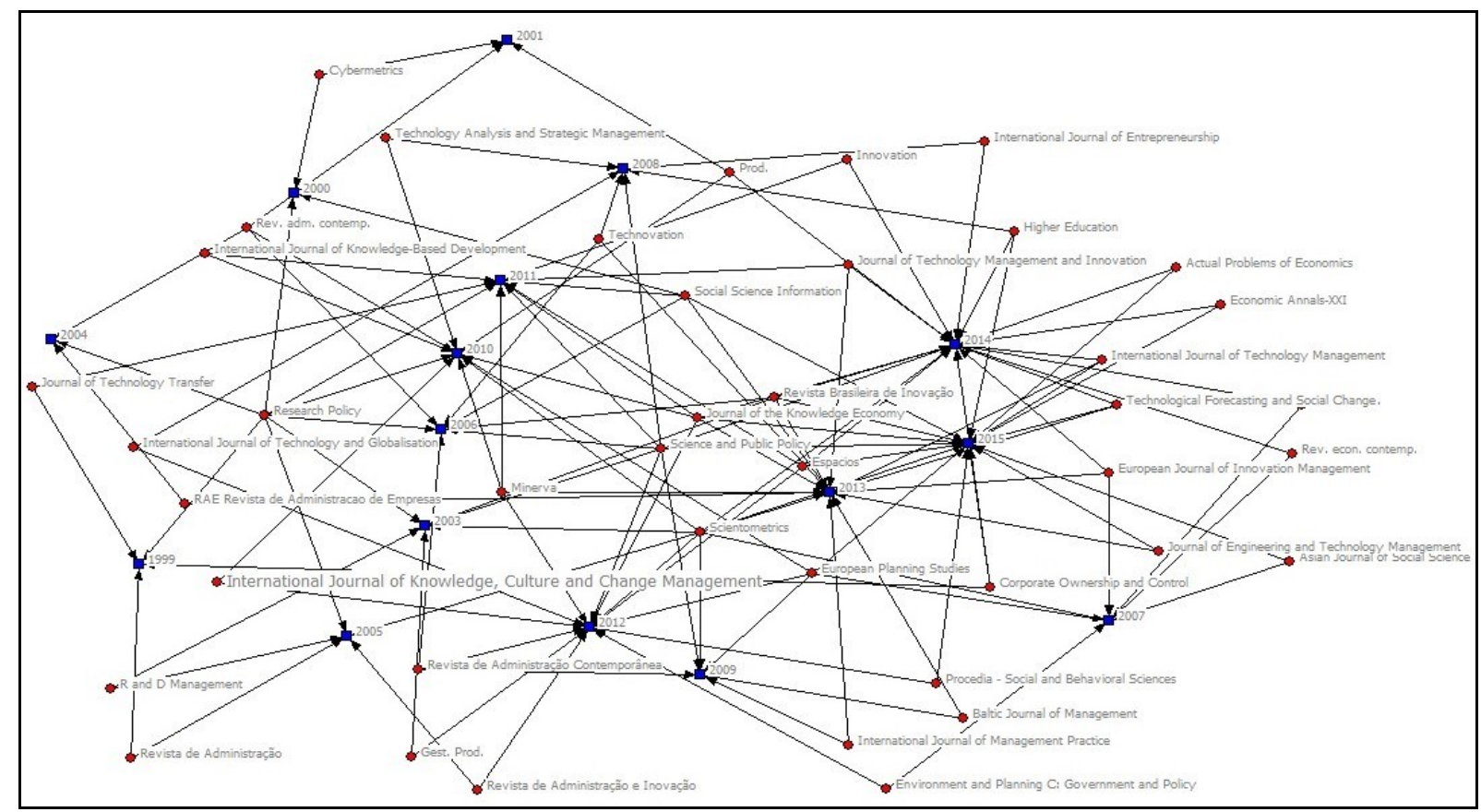

Fonte: Dados da pesquisa. 


\section{O MODELO DA HÉLICE TRÍPLICE: \\ PRODUÇÃO INTELECTUAL EM PERIÓDICOS NACIONAIS E INTERNACIONAIS \\ DOI: http://dx.doi.org/10.5007/1983-4535.2018v11n2p110}

A Figura 2 indica maior representatividade do tema nos últimos anos, tendo maiores ligações em 2012, 2013, 2014 e 2015. Por limitações didáticas, estes dados correspondem somente as principais revistas/journals, sendo incluídos apenas aqueles que tiveram quatro ou mais publicações relacionadas a temática pesquisada. Este corte é justificado pelo elevado número de periódicos (147), que se considerados na totalidade tornaria a rede incompreensiva.

Esta pesquisa teve intuito também de avaliar as autorias dos trabalhos voltados para a universidade-empresa e em consequência o modelo da hélice tríplice. Nos achados dos 356 artigos relacionados ao tema, foram identificadas desde autorias individuais até produções com 5 autores ou mais.

Conforme achados da pesquisa, 616 autores participaram na elaboração das 356 publicações. Com o objetivo de efetuar a rede de coautorias de forma compreensiva para a análise, foram considerados somente os autores principais, os quais foram selecionados a partir do critério de ter publicado dois ou mais artigos como autores principais da pesquisa. Este critério foi estabelecido a partir da constatação de que, com a utilização dos 616 autores, a rede tornava-se incompreensiva. A partir destas definições, foram relacionados 125 autores, constituindo a rede exposta na Figura 3.

A análise da Figura 3 permite a verificação de que os principais autores do tema são H. Etzkowitz e L. Leydesdorft. Os demais autores representam menores ligações como autores principais, vários repetem suas participações em outros artigos como coautores, porém de forma menos expressiva.

H. Etzkowitz e L. Leydesdorft possuem 19 artigos cada autor, considerando produções individuais e como autor principal, sem incluir as coparticipações nos demais trabalhos. No período entre 1995 e 1996, H. Etzkowitz (professor da Universidade do Estado de Nova York) e L. Leydesdorft (professor da Universidade de Amsterdam) desenvolveram vários trabalhos pioneiros com a abordagem da hélice tríplice das relações universidade-indústriagoverno, de forma conjunta. Destes estudos conjuntos, foram desencadeadas diversas outras parcerias em períodos seguintes (ETZKOWITZ, 2013). 
Figura 3 Visualização da rede de coautoria entre os principais autores

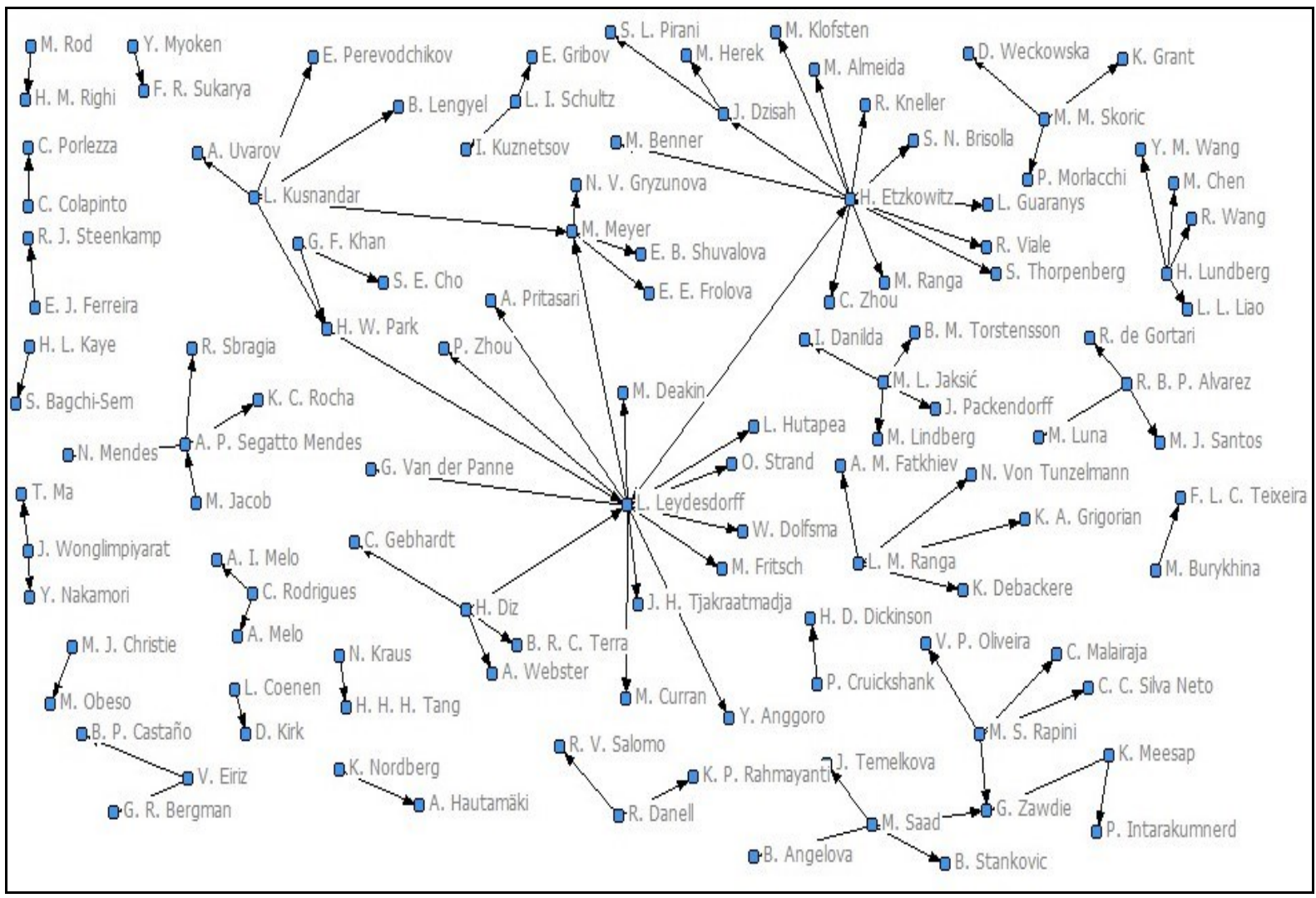

Fonte: Dados da pesquisa.

Em especial, H. Etzkowitz é reconhecido na área pela autoria do livro The triple helix: university-industry-government innovation in action (hélice tríplice: universidade-indústriagoverno inovação em movimento). Esta obra é considerada, principalmente no Brasil, como fonte de referência na área, apresentando informações detalhadas e fundamentais para a compreensão e entendimento do assunto. O livro foi publicado primeiramente em 2008, pela Routledgde, posteriormente traduzido e publicado no Brasil.

Os dados disponibilizados a partir da pesquisa efetuada possibilitou a verificação da quantidade de autoria por artigo, conforme especificado na Tabela 2.

Tabela 2 Quantidade de autores por artigo

\begin{tabular}{c|c|c|c}
\hline Autor(es) por artigo & Número de artigos & $\mathbf{\%}$ & \% acumulado \\
\hline 1 & 95 & $27 \%$ & $27 \%$ \\
2 & 132 & $37 \%$ & $64 \%$ \\
3 & 79 & $22 \%$ & $86 \%$ \\
4 & 32 & $9 \%$ & $95 \%$ \\
5 ou mais & 18 & $5 \%$ & $100 \%$ \\
\hline
\end{tabular}

Fonte: Dados da pesquisa. 


\section{O MODELO DA HÉLICE TRÍPLICE: \\ PRODUÇÃO INTELECTUAL EM PERIÓDICOS NACIONAIS E INTERNACIONAIS \\ DOI: http://dx.doi.org/10.5007/1983-4535.2018v11n2p110}

Analisando a Tabela 2, identifica-se que o percentual mais expressivo individualmente refere-se aos artigos publicados com dois autores, representando 37,5\% do total. Outro dado importante extraído da Tabela 2 refere-se às publicações individuais, representando 26,94\% do total dos artigos analisados. Observa-se que 73,06\% dos artigos foram publicados em coautoria, o que indica boa colaboração entre os pesquisadores.

A Tabela 3 mostra os 11 artigos que receberam o maior número de citações, em números absolutos e relativos. O número absoluto quantifica o total de citações obtidas pelo artigo ao longo do tempo e o número relativo pondera o volume de citações em relação à idade do artigo (citação absoluta $\div$ idade do artigo).

Tabela 3 Artigos com maior impacto, idade e volume de citações

\begin{tabular}{l|c|c|c|c}
\hline Artigos & $\begin{array}{c}\text { Idade } \\
\text { dos } \\
\text { artigo }\end{array}$ & $\begin{array}{c}\text { Citação } \\
\text { absoluta }\end{array}$ & \%* & $\begin{array}{c}\text { Citação } \\
\text { Relativa** }\end{array}$ \\
\hline H. Etzkowitz; L. Leydesdorff (2000) & 16 & 1465 & $21,27 \%$ & 92 \\
H. Diz; A. Webster; C. Gebhardt; B. R. C. Terra (2000) & 16 & 588 & $8,54 \%$ & 37 \\
L. Leydesdorff; H. Etzkowitz (1996) & 20 & 222 & $3,22 \%$ & 11 \\
P. Cooke (2005) & 11 & 182 & $2,64 \%$ & 17 \\
I. F. Aguillo; C. H. Zambrano; O. Z. Florángel (2009) & 7 & 143 & $2,08 \%$ & 20 \\
R. Dagnino (2003) & 13 & 138 & $2,00 \%$ & 11 \\
H. Etzkowitz; M. Klofsten (2005) & 11 & 125 & $1,81 \%$ & 11 \\
A. Inzelt (2004) & 12 & 122 & $1,77 \%$ & 10 \\
M. S. Rapini (2007) & 9 & 120 & $1,74 \%$ & 13 \\
L. Leydesdorff (2000) & 16 & 116 & $1,68 \%$ & 7 \\
M. B. M. Zweekhorst; U. Sandström (2000) & 16 & 108 & $1,57 \%$ & 7 \\
\hline
\end{tabular}

*Proporção calculada com base no total de citações (6.889)

**Citação absoluta $\div$ Idade do artigo

Fonte: dados da pesquisa.

Os dados referentes ao impacto dos artigos foram obtidos na base de dados Scopus (2015), para os artigos internacionais e nas publicações nacionais foram coletadas no Google Acadêmico (2015), no mês de novembro/2015. Foram constatadas 6.889 citações, representando uma média de pouco mais de 19 citações por artigo. O artigo com mais representatividade de citações na área, conforme consta na Tabela 3, é de autoria de H. Etzkowitz e L. Leydesdorff, publicado no ano de 2000 sob o título 'The dynamics of innovation: From National Systems and "mode 2" to a Triple Helix of university-industrygovernment relations', que no momento da pesquisa havia sido citado 1.465 vezes. 


\section{O MODELO DA HÉLICE TRÍPLICE: \\ PRODUÇÃO INTELECTUAL EM PERIÓDICOS NACIONAIS E INTERNACIONAIS \\ DOI: http://dx.doi.org/10.5007/1983-4535.2018v11n2p110}

Outra análise possibilitada é referente à quantidade de artigos por tipo de linguagem (idioma). A linguagem de cada artigo varia, na maioria das vezes, conforme o país da publicação, tendo nos achados da pesquisa 7 linguagens diferentes. $\mathrm{Na}$ Tabela 4, identifica-se a quantidade e a frequência de publicações conforme o tipo da linguagem.

Tabela 4 Quantidade de artigo por linguagem

\begin{tabular}{c|c|c}
\hline Linguagem & N & \% \\
\hline Chinês & 1 & 0,28 \\
Inglês & 295 & 80,87 \\
Espanhol & 8 & 2,25 \\
Francês & 1 & 0,28 \\
Alemão & 1 & 0,28 \\
Português & 48 & 13,76 \\
Russo & 1 & 0,28 \\
\hline \multicolumn{2}{|c}{} \\
\hline
\end{tabular}

Fonte: Dado da pesquisa

Os dados disponibilizados na Tabela 4 indicam a grande quantidade de publicações de artigos em inglês (295 artigos pesquisados), representando uma frequência de $80,87 \%$ do total. Em seguida aparecem as publicações em português (48 artigos), sendo 13,76\% do total; as publicações em espanhol totalizam $2,25 \%$ do total ( 8 artigos) e em chinês, francês, alemão e russo consta 1 artigo em cada linguagem, com frequência de $0,28 \%$, respectivamente.

As leis bibliométricas são utilizadas na verificação da frequência, da qualidade dos trabalhos científicos e da produtividade dos investigadores, entre outras situações. Assim, por exemplo, o impacto e a frequência de citações, normalmente, são utilizados para avaliar o desempenho das revistas científicas, dos investigadores, das instituições e dos países (ROQUE, 2012).

A Tabela 5 demonstra a produtividade por autor, considerando-se os pressupostos da Lei de Lotka para o cálculo de contagem completa, ou seja, autores e coautores receberam a mesma pontuação (URBIZAGASTEGUI, 2008).

Os resultados constantes na Tabela 5 indicam que a frequência de autores com uma única produção representa $79,19 \%$ dos pesquisadores envolvidos. Os achados estão em linha com a constatação de Urbizagastegui (2008, p. 96) de que "a elevada taxa de pequenos produtores parece ser característica das disciplinas em expansão e desenvolvimento na procura de sua institucionalização". 
Tabela 5 Produtividade por autor

\begin{tabular}{c|c|c|c}
\hline $\begin{array}{c}\text { Artigos } \\
\text { por } \\
\text { autor (n) }\end{array}$ & $\begin{array}{c}\text { Número } \\
\text { autores } \\
\text { absoluto } \\
(\mathbf{X})\end{array}$ & $\begin{array}{c}\text { \% de } \\
\text { autores } \\
\text { absoluto }\end{array}$ & $\begin{array}{c}\mathbf{N}^{\mathbf{0}} \mathbf{d e} \\
\text { autores } \\
\text { estimados } \\
\text { Lei de } \\
\text { Lotka*(Y) }\end{array}$ \\
\hline 1 & 487 & $79,19 \%$ & 487 \\
2 & 112 & $18,21 \%$ & 122 \\
3 & 10 & $1,63 \%$ & 54 \\
4 & 3 & $0,49 \%$ & 30 \\
11 & 1 & $0,16 \%$ & 4 \\
24 & 1 & $0,16 \%$ & 0,85 \\
30 & 1 & $0,16 \%$ & 0,54 \\
\hline
\end{tabular}

$*^{Y_{2}}=X_{1} \frac{1}{n^{2}}$

Fonte: Dados da pesquisa.

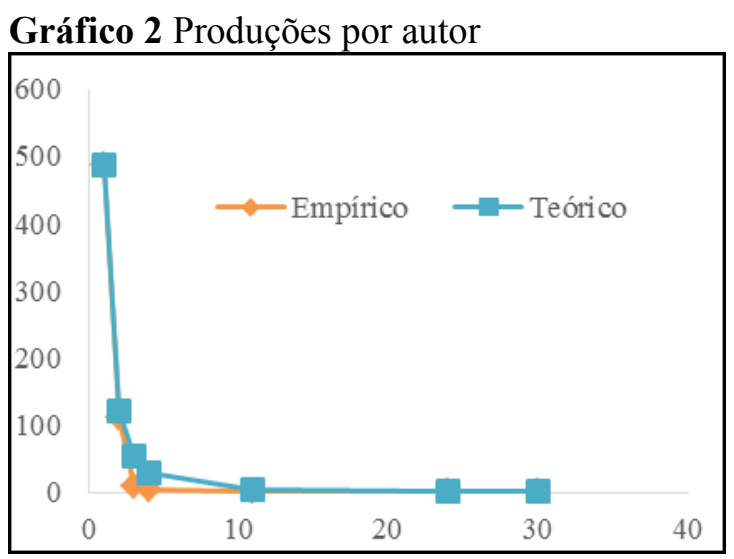

Fonte: Dados da pesquisa.

Com base nos resultados apresentados na Tabela 5, observa-se pelo Gráfico 2 a distribuição gráfica em forma de $\mathrm{J}$ inverso com uma longa cauda de pequenos produtores (STWART, 1994). Na concepção de Urbizagastegui (2008), a cauda em formato de J inverso, representado no Gráfico 2, condiz com o padrão de queda acentuada dos autores que produzem um artigo para os demais e tende à linearidade à medida que vai aumentando o número de publicações por autor. Os dados utilizados para a realização do gráfíco são oriundos da quantidade absoluta dos achados da pesquisa em comparação aos resultados estimados pela Lei Lotka. Assim, observa-se que os dados empíricos coadunam o pressuposto teórico advindo da Lei de Lotka, ao passo que as duas linhas do Gráfico 2 estão praticamente sobrepostas.

De acordo com a Lei de Bradford, a produção está dividida em três zonas, cada qual com $1 / 3$ do total das publicações. Neste estudo em específico, cada zona corresponde a 119 artigos (356/3). A primeira zona forma o core da pesquisa e os dois restantes são as extensões do mesmo. Na Tabela 6, a Zona 1 representa o core principal, com a nomeação dos periódicos pertencentes e as informações das extensões. 
Tabela 6 Lei de Bradford

\begin{tabular}{|c|c|c|c|}
\hline Zona & Periódicos & $\mathrm{N}^{\circ}$ de artigos & Lei de \\
\hline \multirow{6}{*}{$\begin{array}{l}\overline{\tilde{\sigma}} \\
\text { N }\end{array}$} & Scientometrics & 35 & \multirow{6}{*}{$\begin{array}{l}\frac{1}{\widetilde{0}} \\
\text { U }\end{array}$} \\
\hline & Science and Public Policy & 26 & \\
\hline & Research Policy & 21 & \\
\hline & Procedia - Social and Behavioral Sciences & 17 & \\
\hline & Journal of the Knowledge Economy & 10 & \\
\hline & Technological Forecasting and Social Change & 10 & \\
\hline Zona 2 & 31 periódicos & 118 & \multirow{2}{*}{ Extensões } \\
\hline Zona 3 & 110 periódicos & 119 & \\
\hline
\end{tabular}

Fonte: Dados da pesquisa.

Por questões didáticas, devido à grande quantidade de periódicos pertencentes nas zonas 2 e 3, não foram identificados na Tabela 6. Verificando-se a Zona 1, a qual integra o core da pesquisa, evidencia-se a maior concentração de publicações no exterior, com destaque principal ao periódico Scientometrics, que apresentou 35 publicações relacionadas a temática do modelo da hélice tríplice.

A quantidade total de periódicos científicos identificados foi de 147. Além das quantidades em cada periódico descritas na Tabela 6 , identificou-se a seguinte distribuição apresentada na Tabela 7:

Tabela 7 Distribuição dos artigos nas Zonas 2 e 3

\begin{tabular}{cc|cc}
\hline Artigos publicados & $\mathrm{N}^{\text {o }}$ de periódicos & Artigos publicados & $\mathrm{N}^{\mathbf{o}}$ de periódicos \\
\hline 9 & 1 & 4 & 2 \\
8 & 1 & 3 & 8 \\
7 & 4 & 2 & 21 \\
6 & 2 & 1 & 101 \\
5 & 1 & TOTAL & $\mathbf{1 4 1}$ \\
\hline
\end{tabular}

Fonte: Dados da pesquisa.

No âmbito nacional, as duas revistas brasileiras com maior representatividade de artigos são a Revista Brasileira de Inovação e a Revista de Administração, ambas com 7 produções. Neste ponto, denota-se a baixa expressividade das publicações nacionais em relação aos demais países, indicando a existência de um campo abrangente para pesquisas nacionais.

No tocante aos assuntos de maior predominância nos artigos analisados, aplicou-se a Lei de Zipf para analisar a frequência das palavras-chave estabelecidas pelos autores. As palavras-chaves com maior representação, em relação ao total de termos, nos artigos pesquisados são: tríplice hélice $(11,4 \%)$; inovação $(7,8 \%)$; pesquisa acadêmica $(4,8 \%)$; 


\section{O MODELO DA HÉLICE TRÍPLICE: \\ PRODUÇÃO INTELECTUAL EM PERIÓDICOS NACIONAIS E INTERNACIONAIS \\ DOI: http://dx.doi.org/10.5007/1983-4535.2018v11n2p110}

desenvolvimento (4,13\%); interação universidade-empresa (2,13\%); universidade e empresário $(0,8 \%)$.

Os achados mencionados revelam o crescimento e a importância atribuídos pelo mundo acadêmico nos últimos anos referente ao tema da hélice tríplice. Sendo que, com os dados pesquisados pode-se ter uma visão mais ampla das publicações e seus direcionamentos.

\section{CONSIDERAÇÕES FINAIS}

O artigo investigou as principais características da produção intelectual em periódicos nacionais e internacionais, relacionadas à temática do modelo da hélice tríplice, atendendo ao objetivo proposto. A amostra investigada na pesquisa foi constituída de 356 artigos oriundos da base de dados Spell, Scopus, Sciencedirect e Scielo.

Os resultados revelaram que as primeiras publicações iniciaram-se em 1990. Mas, somente a partir do ano 2000 foi que o tema, hélice tríplice, começou a despertar maior interesse no mundo acadêmico. Constatou-se uma expressiva ascensão a partir de 2010.

Foram identificados 616 autores que participaram na elaboração das 356 publicações analisadas. Dentre os principais autores destacaram-se H. Etzkowitz e L. Leydesdorft, com 19 artigos cada, considerando somente produções individuais e como autor principal, sem incluir as coparticipações nos demais trabalhos. Ressalta-se que no período entre 1995 e 1996, H. Etzkowitz (professor da Universidade do Estado de Nova York) e L. Leydesdorft (professor da Universidade de Amsterdam) desenvolveram, conjuntamente, diversos trabalhos pioneiros com a abordagem da hélice tríplice e que desencadearam diversas outras parcerias em períodos seguintes.

Percebeu-se também que o número de artigos realizados em parceria $(73,06 \%)$ foi bastante superior ao de artigos produzidos individualmente (26,94\%), sendo que que a maioria das produções foi realizada por dois autores, representando 37,5\% do total. Além disso, foram constatadas 6.889 citações, ou seja, uma média de pouco mais de 19 citações por artigo. O artigo com mais representatividade de citações sobre o tema é o de autoria de H. Etzkowitz e L. Leydesdorff, publicado no ano de 2000 sob o título 'The dynamics of innovation: From National Systems and "mode 2" to a Triple Helix of university-industry-government relations', que no momento da pesquisa havia sido citado 1.465 vezes.

Em relação a linguagem de cada artigo, constatou-se que varia, na maioria das vezes, conforme o país da publicação, tendo sido identificados 7 idiomas diferentes. A maioria 


\section{O MODELO DA HÉLICE TRÍPLICE: \\ PRODUÇÃO INTELECTUAL EM PERIÓDICOS NACIONAIS E INTERNACIONAIS \\ DOI: http://dx.doi.org/10.5007/1983-4535.2018v11n2p110}

absoluta dos artigos foi escrita em inglês, que correspondem a $80,87 \%$ do total. Dentre os periódicos, aquele que mais publicou artigos relacionados à temática foi o Scientometrics, com 35 publicações.

Em relação a Lei de Lotka, os achados empíricos acenaram para uma falta de consolidação do tema e da ausência de um corpo de autores supostamente de maior prestígio. A Lei de Bradford indicou que o core desta temática está contemplado pelos periódicos: Scientometrics; Science and Public Policy; Research Policy; Procedia - Social and Behavioral Sciences; Journal of the Knowledge Economy; e Technological Forecasting and Social Change, que no conjunto somaram 119 artigos. Por fim, com base na Lei Zipf, as principais palavras-chaves encontradas foram: tríplice hélice, inovação, pesquisa acadêmica, desenvolvimento, interação universidade-empresa, universidade e empresário.

A busca por um estudo bibliométrico foi motivada pela condição do método em analisar os aspectos quantitativos da produção, disseminação e uso da informação registrada, permitindo conhecer de modo mais aprofundado uma determinada temática e seu estado da arte.

Esta pesquisa contribuiu para a compreensão da temática e possibilitou constatar as características das produções no contexto nacional e internacional, servindo de insights para estudos mais específicos. Como recomendação para trabalhos futuros, cabe sugerir que sejam analisadas as publicações específicas dos autores H. Etzkowitz e L. Leydesdorft, para averiguação das semelhanças, originalidade e demais características existentes entre as publicações destes dois autores, considerando que são os autores de maior destaque neste campo de investigação.

\section{REFERÊNCIAS}

ALVARADO, R. U. A Bibliometria: história, legitimação e estrutura. In: TOUTAIN, L. M. B. (Org). Para entender a ciência da informação. Salvador: EDUFBA, 2007. p. 185-217.

ARAÚJO, C. A. Bibliometria: evolução histórica e questões atuais. Em Questão, v. 12, n. 1, p. 11-32, 2006.

BATES, M. J. Document familiarity, relevance, and Bradford's Law: the getty online searching project report. Information Processing \& Management, v. 32, n. 6, p. 697-707, 1996. 


\section{O MODELO DA HÉLICE TRÍPLICE: \\ PRODUÇÃO INTELECTUAL EM PERIÓDICOS NACIONAIS E INTERNACIONAIS \\ DOI: http://dx.doi.org/10.5007/1983-4535.2018v11n2p110}

BENEDETTI, M. H.; TORKOMIAN, A. L. V. Uma análise da influência da cooperação Universidade-Empresa sobre a inovação tecnológica. Gestão e Produção, v. 18, n. 1, p. 145$158,2011$.

BRASIL. Ministério da Ciência e Tecnologia. Livro branco: ciência, tecnologia e inovação. Brasília: Ministério da Ciência e Tecnologia, 2002.

CHUNG, C. J.; PARK, H. W. Mapping Triple Helix innovation in developing and transitional economies: webometrics, scientometrics, and informetrics. Scientometrics, v. 99, n. 1, p. 1-4, 2014.

CLOSS, L.; FERREIRA, G. Transferência de Tecnologia Universidade-Empresa: uma Revisão das Publicações Científicas Brasileiras no período de 2005-2009. In: ENANPAD, 34., Rio de Janeiro - RJ. Anais... Rio de Janeiro: ANPAD, 2010.

CORTEZIA, S. L. D. Internacionalização e Aprendizagem: um estudo sobre as micro e pequenas empresas da indústria de software do Estado do Rio Grande do Sul (Brasil). 2007. 188 f. Dissertação (Mestrado em Administração) - Universidade do Vale do Rio dos Sinos, São Leopoldo, 2007.

CUNHA, C. R. Perspectivas teóricas de análise das relações interorganizacionais. In: ENCONTRO DE ESTUDOS ORGANIZACIONAIS, 2., 2002, Recife. Anais... Recife: EnANPAD, 2002.

DUDZIAK, E. A.; PLONSKY G.A. Lei de inovação e pesquisa acadêmica. Revista de Gestão Industrial, v. 04, n. 01, p. 01-18, 2008.

ETZKOWITZ, H. Hélice Tríplice - Universidade - Indústria - Governo. Porto Alegre: EDIPUCRS, 2013.

ETZKOWITZ, H.; LEYDESDORFF, L. The triple helix: university, industry, government relations: a laboratory for knowledge based economic development. In: THE TRIPLE HELIX OF UNIVERSITY, INDUSTRY, AND GOVERNMENT RELATIONS: the future Location of Research Conference, 1996, Amsterdam. Anais... Amsterdam, 1998.

The triple helix of university-industry-government relations: introduction. Industry and Higher Education, v. 4, n. 1, p. 197-258, 1998.

The dynamics of innovation: from national systems and "mode 2 " to a triple helix of university-industry-government relations. Research Policy, v. 29, n. 2, p. 109-123, 2000.

GIL, A. C. Métodos e Técnicas de Pesquisa Social. 6. ed. São Paulo: Atlas, 2010.

GUEDES, V. L. S.; BORSCHIVER, S. Bibliometria: uma ferramenta estatística para a gestão da informação e do conhecimento, em sistemas de informação, de comunicação e de avaliação científica e tecnológica. In: CINFORM Encontro Nacional da Ciência da Informação, 6. 2005, Salvador. Anais... Salvador, 2005. 


\section{O MODELO DA HÉLICE TRÍPLICE: \\ PRODUÇÃO INTELECTUAL EM PERIÓDICOS NACIONAIS E INTERNACIONAIS \\ DOI: http://dx.doi.org/10.5007/1983-4535.2018v11n2p110}

KIM, J.-Y.; LEE, M.-J. Living with casinos: The triple-helix approach, innovative solutions, and big data. Technological Forecasting and Social Change, 2016.

KLEVORICK, A. K.; LEVIN, R.; NELSON, R. R.; WINTER, S. On the sources and significance of inter-industry differences in technological opportunities. Research Policy, v. 24, n. 2, p. 185-205, 1995.

LUDKE, M.; ANDRÉ, M. E. D. A. Pesquisa em Educação: abordagens qualitativas. 2. ed. Rio de Janeiro: E.P.U, 2013.

MACIAS-CHAPULA, C. A. O papel da informetria e da cienciometria e sua perspectiva nacional e internacional. Ciência da Informação, v. 27, p. 134-140, 1998.

MAMFRIM, F. P. B. Representação de conteúdo via indexação automática em textos integrais em língua portuguesa. Ciência da Informação, n. 20, v. 2, p. 191-203, 1991.

MAYA, D. R. E1 Processo de transferencia de tecnologia. In: SOLLEIRO, J.L; CASTAÑÓN, R. (Orgs.). Gestión Tecnológica: conceptos y prácticas. México: PyV, 2008.

MEYER, M.; GRANT, K.; MORLACCHI, P.; WECKOWSKA, D. Triple Helix indicators as an emergent area of enquiry: A bibliometric perspective. Scientometrics, v. 99, n. 1, p. 151$174,2014$.

MOTA, T. L. N. da G. Interação Universidade-Empresa na sociedade do conhecimento: reflexões e realidade. Revista Ciência da Informação, v. 28, n. 1, p. 79-86, 1999.

MUSCIO, A. What drives the university use of technology transfer offices? Evidences from Italy. Journal of Technology Transfer, v. 35, n. 2, p. 181-202, 2010.

PHILLIPS, Fred. Triple helix and the circle of innovation. Journal of Contemporary Eastern Asia, v. 13, n. 1, p. 57-68, 2014.

ROQUE, V. Métricas da informação: o fator de impacto na prática. Revista Egitania Sciencia, v. 10, n. 1, p. 5-35, 2012.

SANTOS, M. J. V. C. Correspondência científica de Bertha Lutz: um estudo de aplicação da Lei de Zipf e ponto de transição de Goffman em um arquivo pessoal. Ponto de Acesso, v. 3, n. 3, p. 317-326, dez. 2009.

SANTOS, R. N. M.; KOBASHI, N. Y. Bibliometria, cientometria, infometria: conceitos e aplicações. Ciência da Informação, v. 2, n. 1, p.155-172, 2009.

SANTOS, M.E.R. Modelos y buenas prácticas para la transferencia de tecnologia de lãs universidades hacia lãs empresas. In: SOLLEIRO, J.L; CASTAÑÓN, R. (Orgs.). Gestión Tecnológica: conceptos y prácticas. México: PyV, 2008.

SBRAGIA, R.; STAL, E.; CAMPANÁRIO, M.; ANDREASSI, T. (Coord.). Inovação: Como vencer esse desafio empresarial. São Paulo: Clio, 2006. 
SCHREIBER, D.; BESSI, V. G.; PUFFAL, D. P.; TONDOLO, V. A. G. Posicionamento estratégico de MPE's com base na inovação através do modelo Hélice Tríplice. Revista Eletrônica de Administração, v. 19, n. 3, p. 767-795, 2013.

SILVA, C. A. F.; VOTRE, S. J. O. Portal da Inovação do MCT e a sinergia entre universidade, empresa e governo no desenvolvimento da educação física. Revista Brasileira de Educação Física Esporte, v. 26, n. 1, p. 161-169, 2012.

SORIA, A. F. Gestão da transferência de tecnologia na interação universidade-empresa. 2011. 189 f. Dissertação (Mestrado em Administração) - Programa de Mestrado em Administração e Negócios da Faculdade de Administração, Universidade Católica do Rio Grande do Sul, Porto Alegre, 2011.

STRAND, Ø.; LEYDESDORFF, L. Where is synergy indicated in the Norwegian innovation system? Triple-Helix relations among technology, organization, and geography. Technological Forecasting and Social Change, v. 80, n. 3, p. 471-484, 2013.

TISOTT, P. B.; NESPOLO, D.; DIAS, D. T.; OLEA, P. M.; MILAN, G. S. Incubadora tecnológica de Caxias do Sul: inovação tecnológica sob a perspectiva da Hélice Tríplice. Administração: Ensino e Pesquisa, v. 15, n. 3, p. 561-561, 2014.

URBIZAGASTEGUI, R. A produtividade dos autores sobre a Lei de Lotka. Ciência da Informação, v. 37, n. 2, p. 87-102, 2008.

VANZ, S. A. S.; STUMPF, I. R. C. Procedimentos e ferramentas aplicadas aos estudos bibliométricos. Revista Informação \& Sociedade: Estudos, v. 20, n. 2, p. 67-75, 2010.

VERLINDE, S.; MACHARIS, C. Innovation in Urban Freight Transport: The Triple Helix Model. Transportation Research Procedia, v. 14, p. 1250-1259, 2016. 